\title{
Immunocytochemical localization of nuclear protamine in boar spermatozoa during epididymal transit
}

\author{
H. Rodriguez-Martinez, J. L. Courtens*, U. Kvist† and L. Plöen \\ Department of Anatomy and Histology, Faculty of Veterinary Medicine, \\ Swedish University of Agricultural Sciences, Box 7011, S-750 07 Uppsala, Sweden; \\ $\uparrow$ Andrology Unit, Department of Clinical Chemistry, Karolinska Hospital, Stockholm, Sweden; and \\ *Station de Physiologie de la Reproduction, INRA, Nouzilly, 37380 Monnaie, France
}

\begin{abstract}
Summary. Protamine was specifically demonstrated in boar spermatozoa collected from the rete testis, caput, corpus and cauda epididymidis and the ejaculate by immunoelectron microscopy, using anti-boar or anti-ram protamine antisera and an indirect post-embedding immunogold technique. Spermatozoa from all collection sites stained after incubation although with different degrees of labelling. Controls were negative. Labelling increased from the rete testis towards the epididymal corpus, where it was most intense, decreasing sharply thereafter. The weakest binding of the assayed antibodies was obtained in the ejaculated spermatozoa but it could be reversed by in-vitro induction of chromatin decondensation with sodium dodecyl sulphate and the metal-chelating EDTA. The finding of a significant decrease in the immunolabelling detected from the corpus epididymidis onwards indicates a critical point for the interaction between DNA and the protamines in boar spermatozoa during the epididymal maturation.
\end{abstract}

Keywords: spermatozoa; epididymis; protamine; immunocytochemistry; electron microscopy; boar

\section{Introduction}

During their passage along the male genital tract and especially in the epididymis, mammalian spermatozoa undergo structural and biochemical changes that are considered to be prerequisites for achieving optimal fertilizing ability (Bedford \& Calvin, 1974a). Among them, the progressive formation of disulphide bonds in the nuclear protamines has been emphasized (Bedford, 1975). These protamines seem to play a role in the final morphogenesis and stabilization of the sperm head (Fawcett et al., 1971; Bedford \& Calvin, 1974a, b; Loir \& Lanneau, 1984). The degree of condensation of the chromatin has been shown to be in direct relation to the fertilizing ability of spermatozoa (Evenson et al., 1980; Rodriguez et al., 1985).

During spermiogenesis in the boar, protamines are incorporated into the nucleus of elongating spermatids in a sequential and specific manner (Courtens et al., 1988). They are closely associated with the DNA, thus forming the highly condensed chromatin of the spermatozoa (Balhorn et al., 1984). During post-testicular transit the sperm chromatin structure is modified, becoming progressively more rigid, mainly through the formation of stabilizing forces in which cysteine thiol groups take part. Decrease of detectable SH-groups and development of a stability susceptible to the action of dithiotreitol (DTT) were taken as evidence that these forces were $\mathrm{S}-\mathrm{S}$ bonds (Bedford \& Calvin, 1974a). However, bonds involving thiols and zinc have also been suggested, since zinc is capable of masking thiols and since DTT also releases zinc from spermatozoa (Kvist et al., 1987a). Indications that zinc contributes to the stability of boar sperm chromatin was recently given when the decondensation of ejaculated spermatozoa was performed with sodium dodecyl sulphate containing zinc-chelating EDTA, i.e. in the absence of S-S cleaving agents (Kvist et al., 1987b). 
The present study was to follow the presence and temporal distribution of immunoreactive nuclear protamine in boar spermatozoa during their transit through the ductus epididymidis. A preliminary report of our results has been published elsewhere (Rodriguez et al., 1988).

\section{Materials and Methods}

Ejaculates were obtained by the gloved-hand method from mature boars with proven fertility $(\mathrm{N}=6)$. Immediately afterwards, the boars were slaughtered and spermatozoa were collected also from the rete testis, and the caput (initial segment, L. Nicander, personal communication), corpus (distal middle segment) and cauda (distal terminal segment) of the epididymis.

In samples from the whole ejaculate, chromatin decondensation was also induced in spermatozoa ( $20 \mu \mathrm{l}$ sperm solution) by exposure $(60 \mathrm{~min}$ ) to l\% sodium dodecyl sulphate (SDS) with $6 \mathrm{~mm}$-EDTA (SDS-EDTA, $180 \mu \mathrm{l}$ ) in 0.05 M-borate buffer, $\mathrm{pH} 9 \cdot 0$. The reaction was run at $60^{\circ} \mathrm{C}$ and stopped by addition of $200 \mu \mathrm{l}$ glutaraldehyde.

All sampled spermatozoa were fixed in a $1 \%$ solution of glutaraldehyde in $0.17 \mathrm{M}$-cacodylate buffer, $\mathrm{pH} 7.2-7 \cdot 4$, for $10 \mathrm{~min}$ at $4{ }^{\circ} \mathrm{C}$. The spermatozoa were washed in cold $0.3 \mathrm{M}$-cacodylate overnight, pelleted by centrifugation $(600 \mathrm{~g} / 10 \mathrm{~min})$ and then rapidly dehydrated through a series of alcohol and embedded in Agar $100^{\circledR}$ resin. Ultrathin sections were cut on an LKB Ultrotome ${ }^{\oplus}$, picked up on naked nickel grids, and etched by flotation on $10 \%$ hydrogen peroxide for $10 \mathrm{~min}$ before the labelling procedure.

After etching, the ultrathin sections were washed in distilled water and sequentially floated, at room temperature, on $1 \%$ casein in $0.03 \mathrm{M}$-phosphate-buffered $0.8 \%(\mathrm{w} / \mathrm{v})$ saline solution (PBS), $\mathrm{pH} 8.3$, for $30 \mathrm{~min}$, then on the primary antiserum (rabbit anti-boar or ram protamine) diluted (1/100) in PBS, pH 8.3, containing $1 \%$ casein, for $2 \mathrm{~h}$. Details of the regimen of antiserum preparation are given by Courtens et al. (1988). After careful washing through PBS (3 times), the grids were incubated in biotinylated goat anti-rabbit immunoglobulins diluted $1 / 40$ in $\mathrm{PBS}, \mathrm{pH} 8 \cdot 3$, containing I \% casein for $30 \mathrm{~min}$. Following another washing (3 times) in PBS, the grids were floated in a $1 \%$ colloidal gold ( $5 \mathrm{~nm}$ diameter)-streptavidin bridge (Amersham ${ }^{\circledR}$, Solna, Sweden) in PBS, pH 8.3, containing $1 \%$ casein for $45 \mathrm{~min}$. The grids were then washed with distilled water (4 times), dried and examined in a Philips 201 EM electron microscope at $60 \mathrm{kV}$ without counterstaining.

Controls included the use of primary antibody previously coupled to an excess antigen, and the omission of the primary or secondary antibodies following the protocol described above.

The numbers of colloidal gold grains per nuclear section and the surface (in $\mu^{2}{ }^{2}$ ) of the nuclear sections were quantitated by using a digitizing pad (MOP, Konron, Messgeräte GMBH, München, West Germany). All the gold grains in the sections of sperm nucleus, including those on or in proximity to the nuclear envelope, were pointcounted, and the area of the respective nucleus traced in 5 non-overlapping electron micrographs $(\times 35000)$ from each incubated sample. At least 50 nuclear sections per collection site and animals were counted. Comparisons in the number of colloidal grains per $\mu \mathrm{m}^{2}$ between sites of sperm collection were done by a 'protected' Student's $t$ test (Snedecor, 1956).

\section{Results}

The thin-sectioned spermatozoa of epididymal and ejaculate samples were stained after completed incubation (Figs la-f). Control incubations were consistently negative (example in Fig. 1g). Under similar conditions of incubation, the use of anti-ram protamine resulted in stronger labelling than the anti-boar protamine.

The immunolabelling was conspicuously uniform in the nuclei of the sectioned spermatozoa, regardless of the site of collection. Most gold grains were bound to the sectioned chromatin (Figs la-f), although a weak labelling was present towards the nuclear envelope (Figs la-c). Background (unspecific) labelling was restricted to patches of gold particles among the sectioned spermatozoa (Figs 1d-g). Sparse labelling was present in the cytoplasm when anti-boar protamine was used (data not shown), and this labelling could not be distinguished from the background when inhibition tests were run.

The degree of nuclear sperm labelling (expressed here as the number of colloidal gold particles per $\mu \mathrm{m}^{2}$ ), however, varied with the site of collection or the pre-treatment of the spermatozoa (Table 1). The labelling increased from the rete testis (Fig. 1a) towards the corpus epididymidis, where it was most intense (Fig. 1c, $P<0.001)$, decreasing thereafter $(P<0.001$; Table 1). The weakest binding of the assayed antibody was obtained in the ejaculated spermatozoa (Fig. le; Table 1). After samples of these ejaculated spermatozoa were submitted to in-vitro nuclear decondensation 

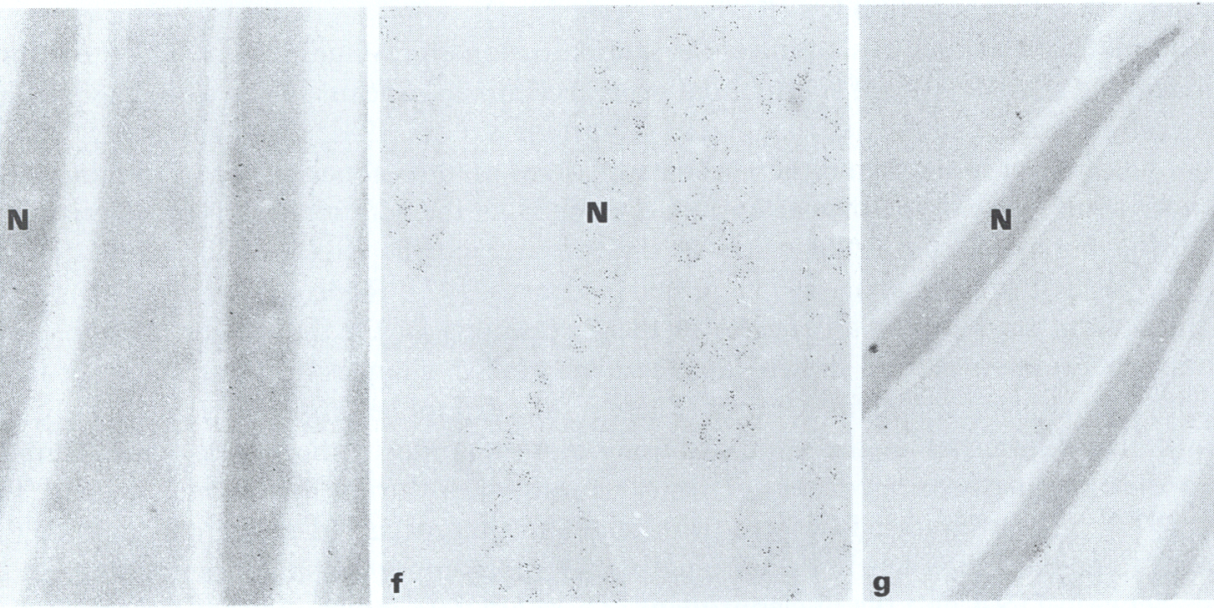

Fig. 1. Thin sections of boar spermatozoa collected from the rete testis (a), the caput (b), corpus $(\mathbf{c}, \mathrm{g})$ and cauda (d) epididymidis and the ejaculate $(\mathbf{e}, \mathbf{f})$. The sections were labelled with antiboar protamine antiserum indirectly coupled to a colloidal gold-streptavidin bridge $(\mathrm{a}-\mathrm{f})$ or with the same antiserum previously coupled to an excess antigen followed by the same incubation protocol $(\mathrm{g})$. In $(\mathrm{a}-\mathrm{f})$ colloidal-gold grains are bound to the sectioned chromatin $(\mathrm{N})$ although a few are present in the nuclear envelope. Ejaculated spermatozoa subjected to chromatin decondensation with SDS/EDTA before fixation and embedding are shown in (f) and $(\mathrm{g})$ is a control section with few background grains. $\mathrm{a}, \mathrm{f}, \mathrm{g}: \times 12000 ; \mathrm{b}, \mathrm{c}, \mathrm{d}, \mathrm{e}: \times 18000$.

Table 1. Number of colloidal gold particles/area of nuclear sections (in $\mu \mathrm{m}^{2}$ ) of boar spermatozoa, collected at different areas of post-testicular transit

\begin{tabular}{|c|c|c|c|c|c|}
\hline \multirow[b]{2}{*}{$\begin{array}{l}\text { Rete testis } \\
(n=62)\end{array}$} & \multicolumn{3}{|c|}{ Epididymis } & \multicolumn{2}{|c|}{ Ejaculate } \\
\hline & $\begin{array}{l}\text { Caput } \\
(n=50)\end{array}$ & $\begin{array}{l}\text { Corpus } \\
(n=63)\end{array}$ & $\begin{array}{l}\text { Cauda } \\
(n=76)\end{array}$ & $\begin{array}{c}\text { No treatment } \\
(n=79)\end{array}$ & $\begin{array}{c}\text { Treatment with } \\
\text { SDS/EDTA } \\
(n=74)\end{array}$ \\
\hline $19 \cdot 0 \pm 27 \cdot 2^{a}$ & $126 \cdot 5 \pm 29 \cdot 9^{b}$ & $376.9 \pm 9 \cdot 4^{\mathrm{c}}$ & $34 \cdot 3 \pm 15 \cdot 6^{\mathrm{a}}$ & $9 \cdot 5 \pm 2 \cdot 9^{\mathrm{a}}$ & $307 \cdot 7 \pm 23 \cdot 5^{c}$ \\
\hline
\end{tabular}

Values are mean \pm s.e.m. for the no. of sections indicated $(n)$ from 6 boars.

Values with different superscripts differ significantly $(P<0 \cdot 05)$. 
with SDS-EDTA before fixation, the labelling increased significantly (Fig. 1f, $P<0.001$ ) with similar numbers of colloidal gold particles per $\mu \mathrm{m}^{2}$ as those found in the corpus epididymidis (Table 1).

\section{Discussion}

The present results indicate regional differences in the accessibility of antibodies against ram and boar protamine to sperm nuclear protamine during the transit of spermatozoa through the ductus epididymidis in the boar. The immunolabelling was uniform within the sectioned sperm nuclei, mostly over the chromatin, and only in a few cases located near the nuclear envelope. In a previous study, the anti-ram and the anti-boar protamine antisera used in the present work recognized protamine in elongating spermatids in boar testes (Courtens et al., 1988). The present immunolocalization of boar protamine by two different antisera, directed against two species-specific protamines, is not surprising, since protamines are highly conservative proteins which are known to cross-react with different antibodies (Rodman et al., 1984).

The ultimate role in nuclear shaping of the spermatozoon is presumably played by the stabilizing disulphide bond cross-linking of spermatidal proteins (Loir \& Laneau, 1984), while the protamines that generally enter the already shaped nuclei (Courtens \& Loir, 1981; Courtens et al., 1988) seem first to stabilize the chromatin and then become involved in its final packaging (Subirana, 1982). It is generally assumed that sperm maturation, if defined as the acquisition of an optimal content of stabilizing bonds, is completed when spermatozoa reach the cauda epididymidis (Calvin \& Bedford, 1971; Bedford \& Calvin, 1974a, b; Beil \& Graves, 1977; Rodriguez et al., 1985).

In the present study, clear differences in the accessibility of the antibodies used to the boar sperm nuclear protamines were shown, and these may reflect changes in the structure of the boar sperm chromatin during epididymal transit. These results cannot be simply interpreted as being due to quantitative differences in the concentrations of protamine in the nuclei, since there is no evidence that spermatozoa incorporate nuclear protamines during epididymal transit (Beil \& Graves, 1977). The pronounced drop in protamine labelling occurred at the corpus/cauda level. This seems to be the region where the chromatin undergoes important changes with respect to the relations between DNA and the nucleoproteins. There are data indicating that the sperm nuclear content of detectable sulphydryl groups decreases sharply from the caput epididymidis to the vas deferens (Pelliciari et al., 1983). Furthermore, cytophotometric studies of Feulgen-DNA in ram spermatozoa have indicated a greater fragility of spermatozoa collected from the body of the epididymidis (Nicolle et al., 1985). These observations indicate that the chromatin is rearranged in this region of the epididymis, together with other sperm functions such as the acquisition of progressive motility (Dacheux, 1980), and fertilizing ability (Hunter et al., 1976). Sperm membrane permeability is maximal in the corpus epididymidis in the bull (Ortavant, 1953), and it is there that changes in sperm metabolism (Orgebin-Crist et al., 1981) and the surface proteins (Voglmayr, 1987; Dacheux et al., 1989) occur.

The differences in labelling seen between the ejaculated spermatozoa before and after in-vitro nuclear decondensation with SDS-EDTA suggest that the labelling seen in ejaculated boar spermatozoa is due to structural rearrangements occurring during epididymal transit by which protamine epitopes become masked. Since EDTA treatment allows decondensation of the highly stabilized sperm nucleus and demasks these epitopes, it is suggested that a divalent cation, possibly zinc, contributes to the stabilization of the DNA-protamine complex (Kvist et al., 1987b; Björndahl et al., 1989). Further studies on zinc metabolism on boar epididymal and ejaculated spermatozoa are in progress.

It has been shown in mice that the antibodies against protamines and the sperm DNA compete for binding sites on the protamines (Rodman et al., 1984). This might also be the case in the boar, and the finding of a significant decrease in the immunolabelling detected from the corpus 
epididymidis onwards, reported here, might indicate a critical point for the interaction between DNA and the protamines in boar spermatozoa during epididymal maturation.

We thank Ms Åsa Jansson for excellent technical assistance. This study received financial support from the Swedish Council for Forestry and Agricultural Research.

\section{References}

Balhorn, R., Weston, S., Thomas, C. \& Wyrobeck, A.J. (1984) DNA packaging in mouse spermatids. Expl Cell Res. 150, 298-308.

Bedford, J.M. (1975) Maturation, transport and fate of spermatozoa in the epididymis. In Handbook of Physiology, Sect. 7, vol. 5, ch. 14, pp. 303-317. Eds D. W. Hamilton \& R. O. Greep. American Physiological Society, Washington, DC.

Bedford, J.M. \& Calvin, H. (1974a) The occurrence and possible functional significance of $\mathrm{S}-\mathrm{S}$ crosslinks in sperm head with particular reference to eutherian mammals. J. exp. Zool. 188, 137-156.

Bedford, J.M. \& Calvin, H. (1974b) Changes in S-S crosslinked structures of the sperm tail during epididymal maturation with comparative observations in submammalian species. J. exp. Zool. 187, 181-204.

Beil, R.E. \& Graves, C.N. (1977) Nuclear decondensation of mammalian spermatozoa: changes during maturation and in vitro storage. J. exp. Zool. 202, 235- 240.

Björndahl, L., Kvist, U., Rodriguez, H. \& Plöen, L. (1989) Cysteine can interact with a metal ion dependent chromatin stability in boar spermatozoa. In Fertilization in Mammals (Serono Symp.), 36, abstr.

Calvin, H. \& Bedford, J.M. (1971) Formation of disulfide bonds in the nucleus and accessory structures of mammalian spermatozoa during maturation in the epididymis. $J$. Reprod. Fert., Suppl. 13, 65-75.

Courtens, J.L. \& Loir, M. (1981) A cytochemical study of nuclear changes in boar, bull, goat, mouse, rat and stallion spermatids. J. Ultrastruct. Res. 74, 327-340.

Courtens, J.L., Plöen, L. \& Loir, M. (1988) Immunocytochemical localization of protamine in the boar testis. J. Reprod. Fert. 82, 635-643.

Dacheux, J.L. (1980) Interactions de l'environment sur l'activité métabolique, la motilité et le pouvouir fécondant des spermatozoides en function de leur état de maturation. Thése Doct. État, Univ. Tours.

Dacheux, J.L., Dacheux, F. \& Paquignon, M. (1989) Changes in sperm surface membrane and luminal protein fluid during epididymal transit in the boar. Biol. Reprod. 40, 635-651.

Evenson, D.P., Darzynkiewicz, Z. \& Melamed, M.R. (1980) Relation of mammalian sperm chromatin heterogeneity to fertility. Science, $N Y \mathbf{2 1 0}, 1131$.

Fawcett, D.W., Anderson, W. \& Phillips, D.M. (1971) Morphogenetic factors influencing the shape of the sperm head. Devl Biol. 26, 220-251.

Hunter, R.H.F., Holtz, W. \& Henfrey, P.J. (1976) Epididymal function in the boar in relation to the fertilizing ability of spermatozoa. J. Reprod. Fert. 46, $463-466$.
Kvist, U., Björndahl, L. \& Kjellberg, S. (1987a) Sperm nuclear zinc, chromatin stability and male fertility. Scanning Microsc. 1, 1241-1247.

Kvist, U., Rodriguez-Martinez, H. \& Plöen, L. (1987b) Is the ejaculated boar sperm chromatin stability determined by the presence of zinc in the seminal plasma? Proc. 7th Workshop Dev. Funct. Reprod. Organs, Turku, p.12, abstr.

Loir, M. \& Lanneau, M. (1984) Structural function of the basic nuclear proteins in ram spermatids. $J$. Ultrastruct. Res. 86, 262-276.

Nicolle, J.C., Fournier-Delpech, S. \& Courot, M. (1985) Influence of uterine secretions on the chromatin of ram spermatozoa at different stages of maturation: Cytophotometric study of Feulgen-DNA after in vitro incubation. Gamete Res. 11, 321-328.

Orgebin-Crist, M.C., Olson, G.E. \& Danzo, B.J. (1981) Factors influencing maturation of spermatozoa in the epididymis. In Intragonadal Regulation of Reproduction, pp. 393-417. Eds P. Franchimont \& C. P. Channing. Academic Press, New York.

Ortavant, R. (1953) Existence d'une phase critique dans la maturation épididymaire des spermatozoides de bélier et de taureau. C. r. Séanc. Soc. Biol. 147, 1552-1556.

Pelliciari, C., Hosokawa, Y., Fukuda, M. \& Manfredi Romanini, M.G. (1983) Cytofluorometric study of nuclear sulphydryl and disulphide groups during sperm maturation in the mouse. $J$. Reprod. Fert. 68, 371-376.

Rodman, T.C., Pruslin, F.H. \& Allfrey, V.G. (1984) Protamine-DNA association in mammalian spermatozoa. Expl Cell Res. 150, 269-281.

Rodriguez, H., Ohanian, C. \& Bustos-Obregón, E. (1985) Nuclear chromatin decondensation of spermatozoa in vitro: a method for evaluating the fertilizing ability of ovine semen. Int. J. Androl. 8, 147-185.

Rodriguez, H., Jansson, \&., Courtens, J.L. \& Plöen, L. (1988) Immunocytochemical localization of nuclear protamines in boar sperm during epididymal transit. J. Ultrastruc. Molec. Struct. Res. 98, 327.

Snedecor, G.W. (1956) Statistical Methods, 5th edn. Iowa State University Press, Ames.

Subirana, J.A. (1982) Nuclear proteins in spermatozoa and their interaction with DNA. In The Sperm Cell, Fertilizing Power, Surface Properties, Motility, Nucleus and Acrosome, Evolutionary Aspects, pp. 197-213. Ed. J. Andre. M. Nijhoff, Dordrecht.

Voglmayr, J.K. (1987) Surface protein changes in ram spermatozoa during maturation and capacitation. In New Horizons in Sperm Cell Research, pp. 3-18. Ed. H. Mori. Japan Sci. Soc. Press, Tokyo.

Received 23 October 1989 